\title{
Prevalence of generalized anxiety disorder in family practice clinics
}

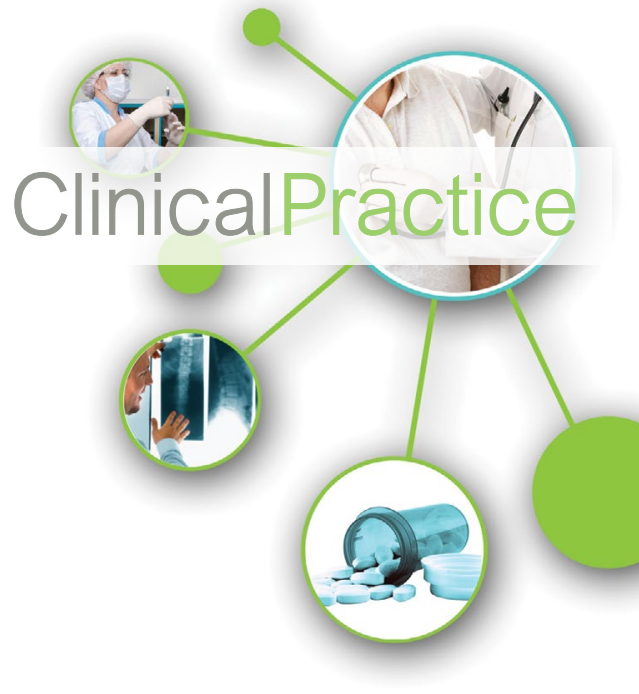

Generalized anxiety disorder is a common mental health in general practice. The aims of this study are to determine the prevalence of generalized anxiety disorder (GAD) among patients attending family practice clinics and its relation to socio-demographic factors and chronic diseases. A cross-sectional design was used on 811 patients over a twomonth period in family medicine clinics at a large teaching hospital in Jordan. This study utilized a self -administered questionnaire that included questions about socio-demographic factors, chronic diseases, and GAD 7-item (GAD7). Patients who were positively diagnosed to have anxiety were then interviewed using DSM-IV criteria to confirm the diagnosis. The prevalence of generalized anxiety disorder was $23.7 \%$. Patients aged 36-45 were five times more likely to have anxiety than other age groups. Women were twice as likely to have GAD as compared to men. Illiterate patients were more likely to have this disorder than others. Patients with a positive family history of anxiety were more diagnosed with GAD than patients with a negative family history, and patients with asthma or arthritis were more likely to develop GAD than other chronic conditions. The prevalence of GAD among patients attending family medicine clinics is relatively high and is associated with socio-demographic factors and chronic diseases, which necessitate enhancing awareness of the prevalence, diagnosis and management of generalized anxiety disorders among family practitioners.

\section{Keywords: Generalized anxiety disorder, family practice, chronic diseases}

\section{Introduction}

Generalized anxiety disorder (GAD) is one of the most common mood disorders and is characterized by periods of increased worry and anxiety for a minimum of 6 months associated with at least three other symptoms of the following: restlessness, muscle tension, sleep disturbance, irritability, difficulty concentrating, and fatigue [1].

The prevalence of GAD in the primary care setting is variable worldwide and estimated to range between (2.4\%-31.2\%) [2-4]. GAD was linked to many contributing factors based on many studies, such as age [5], gender [6], level of education, marital status, family income, living place and religious views [7], each of which was found to affect the probability of getting GAD in a person's life time expectancy [2].

Patients with GAD usually become chronic sufferers as they may have their symptoms for many years before being diagnosed and managed [8]. Many studies showed that people affected with GAD were lower producers in the society and higher users of health care services than other people not affected with GAD [911]. Patients with GAD usually present with somatic symptoms, which are common initial presentations. Examples of such symptoms are chest pain, fatigue, headache, insomnia and abdominal pain [12]. The most common somatic complaint was gastric related symptoms (14.6\%) [13], resulting in difficult detection among primary care settings and only $10 \%$ of them presented to a psychiatrist.

Anxiety disorders have been studied in the gulf area $[14,15]$, while locally in Jordan surveys were done regarding panic disorder [16] and dental anxiety disorder [17] This is the first study that addresses the prevalence of GAD in family medicine practice (FMP), the aim of this study is to find the prevalence of GAD and its association with socio-demographic variables and common chronic diseases.

\section{Methods}

This cross -sectional study was conducted on 811 patients aged 16 and older attending
Farihan F Barghouti ${ }^{1}$, Amina I Al Masalha ${ }^{1}$, Heba Fayyomi ${ }^{1}$, Latifa O Mari' ${ }^{1}$ and Muayyad M Ahmad ${ }^{2 *}$

${ }^{1}$ Department of Family and Community Medicine, The University of Jordan

${ }^{2}$ Department of Clinical Nursing, School of Nursing, The University of Jordan: Amman 11942, Jorda

*Author for correspondence:

mma4jo@yahoo.com 
(FMP) to receive health care for various reasons, in which verbal consent was taken.

Data were collected over two month's duration starting form the first of January 2015 to the end of February 2015 at the family medicine practice. This practice is a training walk-in clinics for all chronic and acute conditions that serve medically insured patients from Amman and surrounding governorates. The study was approved by the ethical scientific research committee at the faculty of medicine and from the ethical committee at the hospital where the study was conducted.

A self-administered validated questionnaire written in Arabic was given to patients who are willing to participate, we excluded patients who are on treatment for anxiety disorders and patients who are mentally incompetent, the process of questionnaire distribution and completion of data were supervised by a staff nurse and two medical students.

The questionnaire consists of three parts, a socio-demographic part, and a part regarding chronic illnesses (diabetes mellitus, hypertension, bronchial asthma, chronic obstructive pulmonary disease (COPD), rheumatologic diseases, thyroid disease and psychiatric illnesses). The third part is GAD7, which is an internationally recognized and validated screening tool for [18].

All participants that scored 10 or more on GAD7 were labeled "positive" and were interviewed by one of the three senior family medicine residents ( who undertake incentive short course in psychiatry), to confirm the diagnosis using DSMIV criteria.

Any participant that did not meet DSMIV criteria for GAD7 was considered negative for GAD7 regardless of GAD7 results. The questionnaire was reviewed for content validity and was pretested for language simplicity and clarity. Reliability was tested on 80 patients who were not part of the study sample prior to starting data collection.

Statistical analysis was done using Statistical Package for Social Sciences (SPSS-IBM, version 25) to analyze sample characteristics in percentage value, the analyses of risk factors associated with anxiety were performed by comparing individuals with positive anxiety diagnosis on DSM-IV on demographics and comorbid conditions. Multiple-group logistic regressions were used to examine the variables of the study, which have three or more unique values; whereas binary logistic regressions were used when the dependent variables have only two groups. With multinomial logistic regression, the assumption is that the odds of preferring one alternative are independent of other alternatives in the variable. Furthermore, when the number of groups is $\mathrm{K}$, the number of independent binary choices is $\mathrm{K}-1$. More specifically, the possible pairs of comparisons in the age groups are five. In addition, the group with the highest number is chosen as the reference alternative in each variable. However, when the alternative within the groups are positive or negative, then the negative one was chosen as the reference group, using odds ratio $(\mathrm{OR})$ and statistical significance of $\mathrm{p}$-value $<.05$

\section{Results}

The total number of participants in the sample was 811 . Women were more than men 573 versus 238 . The age group $36-45$ was the most frequent in our sample $218(26.9 \%)$. Those who were married were more frequent $(70.2 \%)$. Majority of patients were of low income (less than 500Jordanin dinars) (57.2\%). The majority of the sample had a bachelor degree or diploma $n=435$ (53.6\%). Only 70 participants $(8.6 \%)$ had a family history of anxiety. Only 84 participants $(10.4 \%)$ had diabetes. One hundred fifty-five (19.1\%) had hypertension. People with cardiovascular disease comprised $3.1 \%$ of the sample. Those who had asthma were comprised $11.1 \%$ of the sample. People with arthritis accounted for $11.5 \%$ of the sample. About $15.4 \%$ of the sample had dyslipidemia. Only three participants had depression and twelve had gastrointestinal disease (TABLE 1).

The prevalence of generalized anxiety disorder using GAD7 is found to be $23.7 \%$ in our sample. Patients with positive generalized anxiety diagnosis on DSM-IV were 137 (17\%).

TABLE 2 shows the relationship between socio-demographic variables and chronic illnesses with DSMIV anxiety status.

The possibility of anxiety occurrence is almost five times more likely among individuals within the age groups 36-45 as compared to above 65 years $(p<0.05)$. Males are less likely to have anxiety in comparison to females ( $\mathrm{p}=$ 


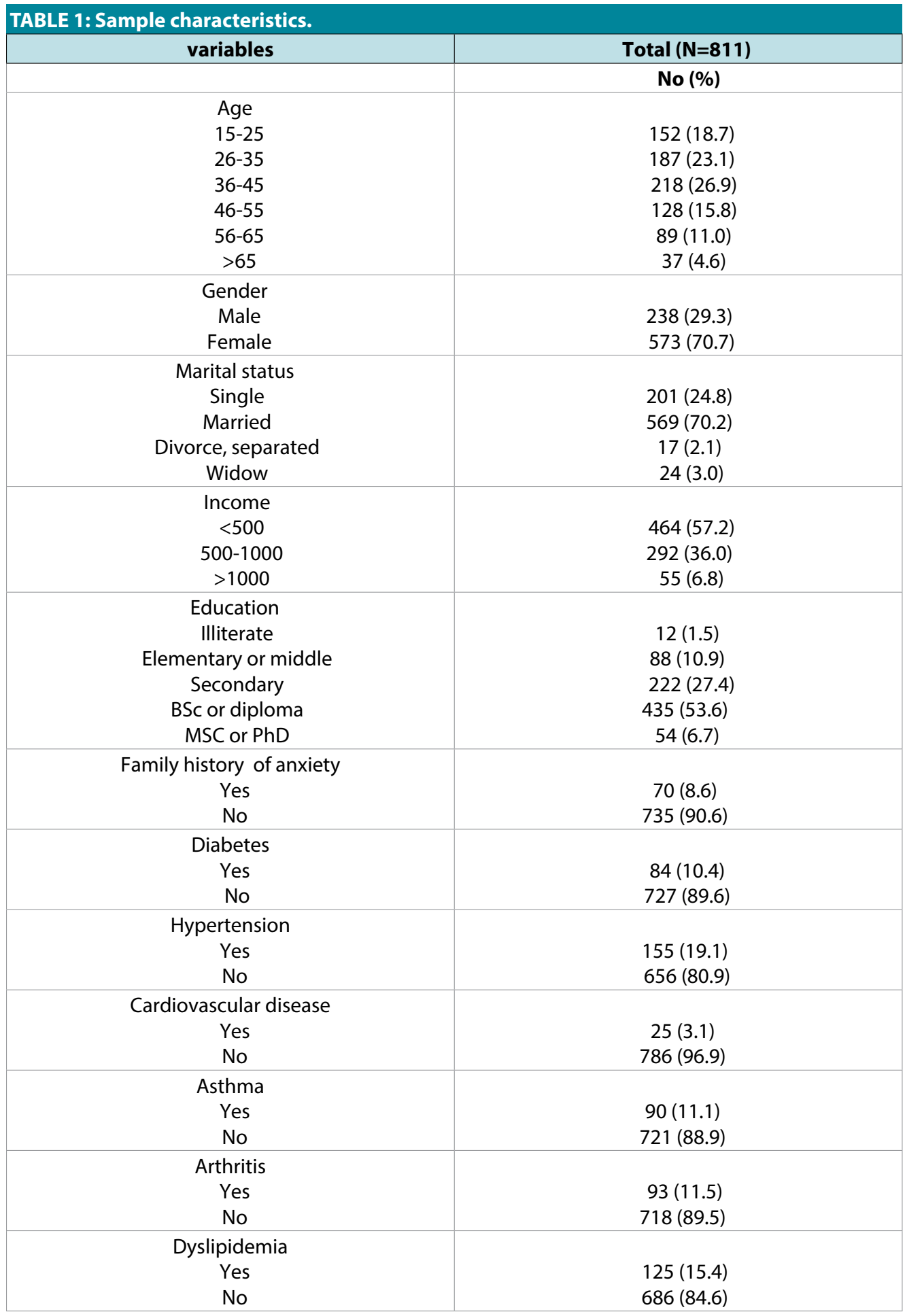

0.002), odds ratio (OR) .48 (95\%CI .30-.77). Illiterate individuals are three times more likely to develop anxiety than educated people OR 3.43 (95\%CI 1.06-11.09) ( $<$ <.05) as compared to those with Bachelor degree and diploma.

Patients with family history of anxiety were almost two times and a half more liable to have anxiety than patients with negative family history of anxiety. A p <.001, with OR 2.47 (95\%CI 1.44-4.25). Participants with history of asthma were almost two times to suffer from anxiety than who are not asthmatic with $\mathrm{p}=$ of .04, OR 1.71 (95\%CI 1.01-2.87). Patient with arthritis were three times more likely to have anxiety than normal ones. $\mathrm{P}<.001$, OR 3.25 (95\%CI 2.02-5.21), 


\begin{tabular}{|c|c|c|c|c|}
\hline Variables & DSM-IV ( $N=137)$ & & & \\
\hline & No (\%) & $p$-value & $\begin{array}{l}\text { Odd ratio } \\
\text { (OR) }\end{array}$ & $\begin{array}{l}\text { 95\%confidence interval } \\
95 \% \mathrm{Cl}\end{array}$ \\
\hline $\begin{array}{c}\text { Age } \\
15-25 \\
26-35 \\
36-45 \text { (reference) } \\
46-55 \\
56-65 \\
>65\end{array}$ & $\begin{array}{c}24(17.5) \\
32(23.4) \\
47(34.3) \\
18(13.1) \\
14(10.2) \\
2(1.5)\end{array}$ & $\begin{array}{l}.17 \\
.26 \\
.09 \\
.25 \\
.04\end{array}$ & $\begin{array}{l}.68 \\
.75 \\
\\
.60 \\
.68 \\
.21\end{array}$ & $\begin{array}{l}.40-1.17 \\
.46-1.24 \\
.33-1.08 \\
.35-1.31 \\
.05-.90\end{array}$ \\
\hline $\begin{array}{l}\text { Gender } \\
\text { Female } \\
\text { Male }\end{array}$ & $\begin{array}{l}112(81.8) \\
25(18.2)\end{array}$ & .002 & .48 & $30-.77$ \\
\hline $\begin{array}{l}\text { Marital status } \\
\text { Single } \\
\text { Married } \\
\text { (reference) } \\
\text { Divorce, } \\
\text { separated } \\
\text { Widow }\end{array}$ & $\begin{array}{c}26(19.0) \\
101(73.7) \\
3(2.2) \\
7(5.1)\end{array}$ & $\begin{array}{l}.12 \\
.99 \\
.16\end{array}$ & $\begin{array}{c}.69 \\
\\
.99 \\
1.91\end{array}$ & $\begin{array}{l}.43-1.10 \\
.28-3.52 \\
.77-4.72\end{array}$ \\
\hline $\begin{array}{c}\text { Income } \\
<500 \text { (reference) } \\
500-1000 \\
>1000\end{array}$ & $\begin{array}{c}87(63.5) \\
45(32.8) \\
5(3.6)\end{array}$ & $\begin{array}{l}.24 \\
.08\end{array}$ & $\begin{array}{l}.79 \\
.43\end{array}$ & $\begin{array}{l}.53-1.17 \\
.17-1.12 \\
\end{array}$ \\
\hline $\begin{array}{l}\text { Education } \\
\text { Illiterate } \\
\text { Elementary or } \\
\text { middle } \\
\text { Secondary } \\
\text { BSc or diploma } \\
\text { (reference) } \\
\text { MSC or PhD }\end{array}$ & $\begin{aligned} 5 & (3.6) \\
22 & (16.1) \\
31 & (22.6) \\
75 & (54.7) \\
4 & (2.9)\end{aligned}$ & $\begin{array}{l}.04 \\
.09 \\
.28 \\
.07\end{array}$ & $\begin{array}{l}3.43 \\
1.60 \\
.78 \\
\\
.38\end{array}$ & $\begin{array}{c}1.06-11.09 \\
.93-2.75 \\
.50-1.23 \\
.14-1.10\end{array}$ \\
\hline $\begin{array}{c}\text { Family history } \\
\text { anxiety } \\
\text { Yes }\end{array}$ & $22(16.1)$ & .001 & 2.47 & $1.44-4.25$ \\
\hline $\begin{array}{l}\text { DM } \\
\text { Yes }\end{array}$ & 15 (10.9) & .80 & 1.08 & $.60-1.95$ \\
\hline $\begin{array}{l}\text { BP } \\
\text { Yes }\end{array}$ & $31(22.6)$ & .25 & 1.30 & $.83-2.02$ \\
\hline $\begin{array}{l}\text { CVD } \\
\text { Yes }\end{array}$ & $7(5.1)$ & .14 & 1.96 & $.80-4.79$ \\
\hline Asthma & & & & \\
\hline Yes & $22(16.1)$ & .04 & 1.71 & $1.01-2.87$ \\
\hline $\begin{array}{l}\text { Arthritis } \\
\text { Yes }\end{array}$ & $33(24.1)$ & .001 & 3.25 & $2.02-5.21$ \\
\hline $\begin{array}{c}\text { Dyslipidemia } \\
\text { Yes }\end{array}$ & $25(18.2)$ & .31 & .78 & $.48-1.27$ \\
\hline
\end{tabular}

\section{Discussion}

In this study we found that the prevalence of generalized anxiety disorder using the GAD7 scale is $23.7 \%$, which is relatively high in comparison to previous studies $[2,3]$ and lower than what other researchers found that generalized anxiety disorder is commonly seen in primary care settings $[4,19,20]$. This high prevalence in our patients could be attributed to many factors. First, this center is located in a country whose political surroundings are quite labile and a difficult economic status that could influence the Jordanian people on a psychological level. On the other hand, most patients attending our family practice are governmentally insured with low income, and 
people with low income usually are at higher risk to suffer from anxiety [21].

In this study we accomplished that the prevalence of GAD varies according to age, it was five times higher among patients of 3645 of age as compared to other age groups. This variation was comparable to other studies [5,22]. This result can be attributed to the stressful factors that tend to cluster in this age group, including work and parenting responsibilities [23]. Patients that present to primary care clinics tend to be middle aged, as it could be more difficult for elderly patients to present to clinics, either for health related reasons or other co-morbidities or due to the denial of having a health issue. In addition, elderly patients might be suffering from anxiety or depression which would prevent them from seeking healthcare in the first place [22], or they could have been treated for GAD which could lower the number of patients diagnosed with it.5 In our study GAD was more prevalent in women, this result was consistent with other studies [6,24].

We also found that people with low level of education were more likely to suffer from anxiety than highly educated people, which is comparable to other studies [25]. Locally in Jordan, a survey was done by The Jordanian Ministry of Labor in 2007-2011 which showed that people who had low level of education were mostly unemployed [26] and the unemployed usually have a lower income which put them at risk of suffering from anxiety [21].

Studies showed that mental disorders including GAD can be associated with chronic illnesses and cause serious consequences to work loss or absence $[27,28]$. In our study, we evaluated the relationship between GAD7 and each of hypertension, diabetes, dyslipidemia, asthma, arthritis and CVD, yet we found no significant association except for a history of arthritis and asthma.

Rheumatoid arthritis (RA) is a severe disabling disease; hence a high level of anxiety is not unexpected. Patients with rheumatologic disorders are common sufferers from anxiety. This might be attributed to the rheumatologic disease itself or its complications such as joint deformity and physical impairment [29].

Patients with rheumatologic disorders commonly present to their rheumatology specialists whose focus is on the disease itself even though it is important to take a holistic approach to the patient and consider and manage the psychological association such as anxiety and depression, which could have a significant impact on those patients [30]. Regarding asthma and anxiety, studies showed that a higher degree of psychosocial stressors were associated with higher incidence of atopic diseases like asthma [31].

The cause for this relation can be referred to environmental factors; families with stressful environment and low social support are more likely to have children with asthma and its physical and psychological complications [32]. The underlying biologic mechanisms between psychological factors and asthma are not clear. Some suggest that neuro-immunomodulatory mechanisms are responsible [33]. In addition, vagus nerve stimulation can cause a psychological influence leading to upper airway constriction [34].

We found that patients with a positive family history of anxiety disorder have a strong risk of suffering from GAD. The mechanism behind this association warrants more studies, the insecure environment for children of parents with anxiety disorder can put them in a place where they cannot cope with stress during their adulthood and turn into having a generalized anxiety disorder, this also was supported in another study that found a good a association between having a family member with anxiety disorder and developing GAD [35].

This study has limitation, the questionnaire used in this study contained self-reported data and the validity of self-reported data has been called for question by some authors. Also this study is cross sectional design which limits the causal references that can be made. Furthermore, we recommend for next studies to measure stress level among participants.

\section{Conclusion}

Our study showed that the prevalence of GAD in Jordan is relatively high, which means that effort must be taken to increase the awareness of its high prevalence, associated sociodemographic factors and chronic diseases and subsequently diagnose and treat those patients who attend primary care centers. Further studies are needed to determine whether diagnosis and intervention for GAD in primary care setting can outcome and reduce cost to our healthcare system.

Conflict of interest: The authors declare no conflict of interest in this study. 


\section{References}

DSM-IV-TR Diagnostic and Statistical manual of mental disorders: text revision, 4th ed. Washington: American psychiatric association (2000).

Kroenke K, Spitzer RL, Williams JB. Anxiety disorders in primary care: prevalence, impairment, comorbidity, and detection. Ann. Intern. Med. 146(5), 317-325 (2007).

Leray E, Camara A, Drapier D, et al. Prevalence, characteristics and comorbidities of anxiety disorders in France: results from the "Mental Health in General Population" survey (MHGP). Eur. Psychiatry. 26(6), 339-345 (2011).

Vermani M, Marcus M, Katzman MA. Rates of detection of mood and anxiety disorders in primary care: a descriptive, cross-sectional study. Prim. Care Companion CNS. Disord. 2011, 13(2).

Brenes GA, Knudson M, McCall WV, et al. Age and racial differences in the presentation and treatment of Generalized Anxiety Disorder in primary care. J. Anxiety. Disord. 22(7),11281136 (2008).

Wittchen HU. Generalized anxiety disorder: prevalence, burden, and cost to society. Depress. Anxiety. 16(4), 162171 (2002).

Qin X, Phillips MR, Wang W, et al. Prevalence and rates of recognition of anxiety disorders in internal medicine outpatient departments of 23 general hospitals in Shenyang, China. Gen. Hosp. Psychiatry. 32(2), 192-200 (2010).

Bruce SE, Yonkers KA, Otto MW, et al. Influence of psychiatric comorbidity on recovery and recurrence in generalized anxiety disorder, social phobia, and panic disorder: a 12-year prospective study. Am. J. Psychiatry. 162(6), 1179-1187 (2005).

Kessler RC, DuPont RL, Berglund P, Wittchen HU: Impairment in pure and comorbid generalized anxiety disorder and major depression at 12 months in two national surveys. Am. J. Psychiatry. 156(12), 1915-1923 (1999).

Maier W, Gänsicke M, Freyberger HJ, Linz M, Heun R, Lecrubier Y. Generalized anxiety disorder (ICD-10) in primary care from a cross-cultural perspective: a valid diagnostic entity? Acta Psychiatr. Scand. 101(1), 29-36 (2000).

Weiller E, Bisserbe JC, Maier W, Lecrubier Y. Prevalence and recognition of anxiety syndromes in five European primary care settings. A report from the WHO study on Psychological Problems in General Health Care. Br. J. Psychiatry. 1998(34),18-23 (1998).

Kroenke K, Spitzer RL, Williams JB, et al. Physical symptoms in primary care. Predictors of psychiatric disorders and functional impairment. Arch. Fam. Med. 3(9), 774-779 (1994).

Souêtre E, Lozet H, Cimarosti I, et al. Cost of anxiety disorders: impact of comorbidity. J. Psychosom. Res. 38(Supp1), 151-160 (1994).

Qureshi NA, Al-Habeeb TA, AlGhamdy YS, Magzoub ME, van der Molen HT. Psychiatric co-morbidity in primary care and hospital referrals, Saudi Arabia. East Mediterr. Health J. 2001, 7(3), 492-501 (2001).

El-Rufaie OE, Al-Sabosy MA, Bener A, Abuzeid MS. Somatized mental disorder among primary care Arab patients: I. Prevalence and clinical and sociodemographic characteristics. J. Psychosom. Res. 46(6), 549-555 (1999).

RA Suleiman, TFE Ahmad. Presence of Panic Disorder Among Patients Referred to Psychiatry. Arab Journal of Psychiatry. 4 (1993).

Ayasrah S, Ahmad M. Educational Video Intervention effects on Periprocedural Anxiety Levels among Cardiac Catheterization Patients: A Randomized Clinical Trial. Res. Theory. Nurs. Pract. 30 (1), 70-84 (2016).

Spitzer RL, Kroenke K, Williams JB, Löwe B. A brief measure for assessing generalized anxiety disorder: the GAD-7. Arch. Intern. Med. 166(10),1 092-1097 (2006).

Sansone RA, Hendricks CM, Gaither GA, Reddington A. Prevalence of anxiety symptoms among a sample of outpatients in an internal medicine clinic: a pilot study. Depress. Anxiety. 19(2), 133-136 (2004).

Kristen Hope Demertzis M, Michelle G. Craske P. Anxiety in primary care. Current Psychiatry Reports 8(4), 291297 (2006).
Wolff BC, Santiago CD, Wadsworth ME. Poverty and involuntary engagement stress responses: examining the link to anxiety and aggression within lowincome families. Anxiety Stress Coping. 22(3), 309-325 (2009).

Ansseau M, Fischler B, Dierick M, Mignon A, Leyman S. Prevalence and impact of generalized anxiety disorder and major depression in primary care in Belgium and Luxemburg: the GADIS study. Eur. Psychiatry. 20(3), 229-235 (2005).

Rayan A, Ahmad M. Effectiveness of Mindfulness-Based Intervention on Perceived Stress, Anxiety, and Depression among Parents of Children with Autism Spectrum Disorder. Mindfulness. 8(3), 677-690 (2017).

Munk-Jørgensen P, Allgulander C, Dahl AA, et al. Prevalence of generalized anxiety disorder in general practice in Denmark, Finland, Norway, and Sweden. Psychiatr. Serv. 57(12), 17381744 (2006).

Mirza I, Jenkins R. Risk factors, prevalence, and treatment of anxiety and depressive disorders in Pakistan: systematic review. BMJ. 328(7443), 794 (2004)

Bani Mohammad E, Ahmad M. Virtual reality as a distraction technique for pain and anxiety among patients with breast cancer: A randomized control trial. Palliat. Support Care. (2018).

Kessler RC, Ormel J, Demler O, Stang PE. Comorbid mental disorders account for the role impairment of commonly occurring chronic physical disorders: results from the National Comorbidity Survey. J. Occup. Environ. Med. 45(12), 1257-1266 (2003).

Wang PS, Beck AL, Berglund P, McKenas DK, Pronk NP, Simon GE, Kessler RC: Effects of major depression on moment-in-time work performance. Am. J. Psychiatry. 161(10), 1885-189 (2004).

Hagglund KJ, Roth DL, Haley WE, Alarcón GS. Discriminant and convergent validity of self-report measures of affective distress in patients with rheumatoid arthritis. J. Rheumatol. 16(11), 1428-1432 (1989).

Waheed A, Hameed K, Khan AM, Syed JA, Mirza AI. The burden of 
anxiety and depression among patients with chronic rheumatologic disorders at a tertiary care hospital clinic in Karachi, Pakistan. J. Pak. Med. Assoc. 56(5), 243247 (2006).

Chida Y, Hamer M, Steptoe A. A bidirectional relationship between psychosocial factors and atopic disorders: a systematic review and meta-analysis. Psychosom. Med. 70(1), 102-116 (2008).

Kaugars AS, Klinnert MD, Bender
BG. Family influences on pediatric asthma. J Pediatr Psychol 29(7), 475-491 (2004).

Wright RJ. Stress and childhood asthma risk: overlapping evidence from animal studies and epidemiologic research. Allergy Asthma Clin. Immunol. 4(1), 2936 (2008).

Isenberg SA, Lehrer PM, Hochron S. The effects of suggestion and emotional arousal on pulmonary function in asthma: a review and a hypothesis regarding vagal mediation. Psychosom. Med. 54(2), 192216 (1992).

McLaughlin KA, Behar E, Borkovec TD. Family history of psychological problems in generalized anxiety disorder. J. Clin. Psychol. 64(7), 905-918 (2008).

This special issue on Current Trends in Clinical Research was edited by Dr. Shweta Gera. 